\title{
Los efectos del mago de la cara de vidrio en los niños
}

\author{
Luzmila Abigail GARCíA GARCÍA*
}

E.A.P. Psicología, Facultad de Ciencias de la Salud, Universidad Peruana Unión, Alt. Km 19; Carretera Central, Lurigancho, Lima

\begin{abstract}
RESUMEN
El objetivo de la investigación es identificar los efectos de la televisión en los niños, para tomar medidas preventivas y de intervención, porque el futuro de la sociedad está en las manos de quienes ahora son los más débiles. La metodología usada fue de diseño no experimental, de tipo descriptivo; una revisión teórica de las investigaciones de la última década sobre la actualidad de esta problemática. En primera instancia, en base a explicaciones teóricas; es necesario conocer que la población infantil es la más vulnerable a los efectos de la televisión, ya que son agentes en constante aprendizaje e imitación. Ante la excesiva e indiscriminada exposición a la televisión se obtuvieron como resultado algunos efectos psicológicos. Encontrándose que puede perjudicar significativamente las funciones cognitivas de atención, concentración y memoria de los niños, afectando directamente su rendimiento académico (Torres y García, 2009). Asimismo, su capacidad de reflexión se ve alterada siendo mucho más propenso a reaccionar en forma violenta (Clausell, 2005). Además la televisión participa en la formación de la identidad de género, lo transforma, lo da a conocer, lo manipula, lo diferencia; de una forma sutil y muchas veces inofensiva; asimismo, parte de la moral y la adquisición de valores se ve influencia por frecuente exposición a la televisión, siendo el ocio y el consumo los más propagados (Veliz, 2005). Finalmente se concluye que es indispensable la selección y supervisión de los programas televisivos a los que son expuestos los niños, ya que los efectos que éstos pueden ocasionar son de gran relevancia.
\end{abstract}

Palabras clave: Efectos, televisión, niños.

\begin{abstract}
The objective of the research is to identify the effects of television on children, to take preventive measures and intervention, because the future of the company is in the hands of those who are now the weakest. The methodology used was non-experimental, descriptive, theoretical review of research in the last decade on this issue today. Firstly, based on theoretical explanations need to know that the child population is the most vulnerable to the effects of the television, as they are constantly learning agents and imitation. Given the excessive and indiscriminate television exposure were obtained as a result some psychological effects. Being that can significantly impair cognitive functions of attention, memory and concentration of children, directly affecting their academic performance (Torres and Garcia, 2009). Also its reflectivity is altered to be much more prone to react violently (Clausell, 2005). Besides television participates in the formation of gender identity, transforms it, makes it known, manipulates it, what difference, in a subtle and often harmless, also, part of the moral and value acquisition is influenced by frequent exposure to television, where entertainment and the most widespread consumption (Veliz, 2005). Finally we conclude that it is essential to the selection and monitoring of television programs to which children are exposed, as the effects they can cause are of great importance.
\end{abstract}

Keywords: Effects, TV, children.

\footnotetext{
*Correspondencia: luzmibi@gmail.com
} 


\section{INTRODUCCIÓN}

En la actualidad el medio televisivo se ha instalado en la vida del hombre y, principalmente en la de los niños, ocupando un lugar y un tiempo privilegiado en sus vidas; progresivamente la televisión se ha ido introduciendo en el entorno doméstico consiguiendo estar presente en la vida cotidiana, y de manera imperceptible, ha abarcado más aspectos conductuales, "por lo que se la considera como algo indispensable y muchas veces se vuelve una necesidad”. (Vilchez, 1999, p. 16).

Esto se evidencia en un estudio realizado por Sevillano y Perlado (2005), quienes encontraron en una muestra de 432 niños españoles que el $84,5 \%$ de los niños se sientan a ver la televisión entre las 7 y las 9:30 de la mañana. Cuando salen del colegio, el 87\% de los niños visualizan algún programa de la televisión. Los fines de semana entre las 9 y las 12 del mediodía el 98,6\% de los niños ven televisión.

En base a estos resultados es relevante mencionar que son los niños los principales espectadores de la televisión, y que ésta, gracias a sus "tácticas persuasivas de transmitir sus contenidos, entretienen y tienen la facultad de moldear la mente de los individuos y, en concreto, la de los niños más pequeños”. (Perlado y Sevillano, 2003 , p. 165); siendo esta población la más vulnerable a sus efectos y paradójicamente quienes más la consumen. Asimismo, la televisión estimula aspectos afectivos y emocionales de la personalidad, teniendo una influencia significativa en las personas con una alta sensibilidad. (Veliz y Maureira, 2005).

A causa de toda esta información expuesta anteriormente es importante saber, de manera específica, cuáles son los efectos de la televisión en los niños, y de esa forma tomar medidas preventivas y de intervención a tiempo, ya que el futuro de la sociedad está en las manos de quienes ahora parecen ser los más débiles y vulnerables. El objetivo de este artículo es poder identificar los efectos de la televisión en los niños, para de esa forma tomar las medidas del caso.

\section{Definición}

El origen etimológico de la palabra televisión deriva del griego "Tele" que significa distancia y latina "visio" que quiere decir (visión). (Diccionario etimológico de Chile, 2012).

Rodriguez y Ruiz (2005), lo definen como un "sistema de telecomunicación para la transmisión y recepción de imágenes en movimiento y sonido a distancia” (p. 2), esta transmisión se realiza a través de ondas de radio o cable. Por otro lado, también se le puede atribuir este término a todos los aspectos de transmisión y programaciones.

A esto Fernández (1994), agrega que la televisión es “un medio de comunicación que ha alcanzado una difusión sin precedentes" (p.12), instalándose significativamente en la vida de las personas, satisfaciendo de esa forma sus necesidades de información y entretenimiento.

Concerniente al televisor Vilain (2001), lo define de una manera peculiar asociándolo a un mago con cara de vidrio, que puede ser muy beneficioso y al mismo tiempo dañino para las personas, resaltando básicamente el uso que cada ser humano decide darle. Es decir, depende de cada persona que el televisor sea bueno o malo.

Por otro lado, Veliz y Maureira (2005), se refieren a la televisión como una fuerza socializadora que transmite cultura, comportamientos, costumbres logrando de esa forma obtener un lugar preponderante, al mismo tiempo que influye en la sociedad, en la cultura, política y economía. Además hacen referencia a una de las características más representativas de la televisión: la inmediatez y actualidad de sus mensajes, puesto que brinda información del momento; lo que aumentaría aún más su importancia social.

Un aspecto relevante que mencionan Veliz y Maureira (2005), es que la televisión estimula aspectos afectivos y emocionales de la personalidad, teniendo una influencia significativa en las personas con una alta sensibilidad.

Entonces se podría definir a la televisión como uno de los medios de comunicación más importantes, con una influencia significativa en la sociedad y en la vida de cada persona.

\section{Reseña Histórica}

Rodríguez y Ruiz (2005), publicaron una breve historia del desarrollo de la televisión a lo largo de la historia. En 1872, se inventa praxinoscopio (sistema para mostrar imágenes en movimiento) por Emite Renand.

1873 Senlecp crea el primer servicio móvil mediante su teoría de la transmisión a distancia de imágenes en movimiento, (descomposición y sucesiva recomposición fragmentaria).

1880, G. R. Carey inventó una forma para mostrar una imagen a distancia por medio de la electricidad. Pero no funcionó ese proyecto.

1897, Ferdinand Braun, físico alemán, aportó en la elaboración de la televisión mediante la creación de un tubo de rayos catódicos (siendo útil para las cámaras modernas); descubrió que ésta brillaba al chocar con 
pintura fluorescente al estudiar el comportamiento de los electrodos.

1900, Perskyi introduce la palabra televisión en una exposición en París.

1906, el ruso Boris Rosing dedujo que el tubo de rayos catódicos podía ser usado para proyectar imágenes de televisión.

En 1911, Rosing solo pudo producir imágenes deficientes. Esto no se considera un fracaso ya que sirvió para crear así el primer aparato de televisión que funcionó en el mundo.

1923 y 1931, Vladimir Zworykin elabora dos grandes inventos, el primer iconoscopio (tubo electrónico para cámara) y un kinescopio (tubo de imagen).

1925, Worykin logró la primera patente de televisión en color, cubriendo la pantalla del tubo de rayos catódicos con filtros de color en cámara. Este invento no tuvo buenos resultados hasta 25 años después con la creación de sistemas electrónicos de color.

1926, se efectúa la primera transmisión para el público por John Logie Baird.

En 1929, se inauguró el primer estudio de televisión del mundo en Long Acre, por Baird; con algunas fallas técnicas, por lo que no se logró transmitir al mismo tiempo las imágenes y el sonido.

En 1930, la NBC en EE.UU. y la BBC en Inglaterra en 1927 transmiten los primeros programas de televisión, ambas con un horario regular.

1935, en Berlin se inaugura el primer servicio del mundo de televisión filmada, su harario de funcionamiento era tres días a la semana por dos horas.

Estas emisiones se interrumpieron debido a la II guerra mundial. Una vez terminada se reapertura nuevamente, siendo España el país más representativo en esta etapa de la televisión.

1970, época dorada de la televisión. Aparece la televisión en color creciendo significativa su producción. Por otro lado, el Centro Regional de Innovación y Formación ACASIA refiere que en estos años la televisión es utilizada para difundir valores democráticos para reemplazar las secuelas del régimen anterior.

1980, el sistema televisivo amplía su horario de emisión e incluyen la franja matutina (hasta entonces solo se emitía en período de tarde y noche). Y empiezan las primeras televisiones autonómicas.

1990, aparecen por primera vez los canales privados, incrementando las ofertas y al mismo tiempo afectando a los canales españoles.

\section{Vulnerabilidad infantil}

A continuación se revisaran algunas explicaciones teóricas que aludían el desarrollo de los niños, señalando sus características; para ser conscientes de cuán vulnerables son y cuánta dirección requieren para un adecuado desarrollo, siendo no precisamente la televisión el mejor tutor en esta edad ya que según Perlado (2003), la mayoría de niños los primeros que hacen al llegar a casa después del colegio es prender la televisión; permaneciendo frente a ella hasta horas de la noche; es decir prácticamente pasa la mayor parte del tiempo en compañía de la televisión.

Tallaferro (2001), explica brevemente la teoría psicosexual de Freud, que hace referencia a una serie de fases psicosexuales resaltando la presencia de una parte erógena en cada etapa: etapa oral, anal, fálica, de latencia y genital. En cada etapa hay eventos significativos, es en la etapa fálica (de 3-6 años) donde los niños experimentan el llamado complejo de Edipo en los niños y Electra en las niñas, en esta edad los niños se sienten atraídos por el progenitor de su sexo opuesto, entrando en un conflicto con el otro progenitor; para encontrar un equilibrio se hace uso del mecanismo de introyección, donde imiten las características del progenitor que consideran su competencia; de esa forma se identifican y empiezan a formar parte de lo que en un futuro se consolidará en su personalidad. De esa forma se entiende que en esta etapa el niño se identificará con lo que más contacto tenga, en esta caso, si pasa más tiempo frente a la televisión es muy probable que se identifique con los personajes de los programas que observa.

Adicionalmente Piaget (1972), considera relevante la inteligencia en el desarrollo del ser humano, creando la teoría psicogenética; distinguiendo dos áreas del desarrollo intelectual de los niños:

Psicosocial: se refiere a todo lo que el niño adquiere desde afuera, aprende mediante los agentes de sociabilización (familiar, escolar o educativa).

Psicológico (espontáneo): es lo que el niño piensa aspectos que no se le ha enseñado, pero que lo aprende porque lo descubre por sí solo.

Este punto de vista considera dos perspectivas fundamentales: La primera hace referencia al proceso de adaptación a través de: la asimilación y la acomodación; la segunda Piaget la llama estructuras. La acomodación de- 
nota la exposición al medio necesaria para la asimilación.

A los seis años los niños entran en la etapa de operaciones concretas (nombre dado por Piaget); de acuerdo a la base teórica, el niño tiene la capacidad de hacer uso de su pensamiento para resolver problemas, haciendo una representación mental de la situación sin necesitar operar sobre la realidad para resolverlo. Empero es necesario considerar que esta facultad gira en función de fenómenos concretos; como consecuencia de la realidad. Por lo tanto, se puede inferir que existe una gran influencia externa en el desarrollo intelectual de los niños, su pensamiento se irá consolidando en base al contexto, el niño asimilará como parte de su persona lo que más común sea para él; entonces se infiere que si la televisión ocupa un lugar preponderante en el desempeño del niño, es muy probable que influya significativamente en su formación.

De acuerdo a la teoría de Erikson a los 5 -13 años se desarrolla la crisis de Industria v/s Inferioridad, desarrollándose el sentimiento de la Competencia. En esta etapa hay una necesidad por la productividad, el dominio de tareas. Hay dos eventos importantes: el desarrollo del autoconcepto y la autoestima del niño.

Entre los 6 y 7 años el niño se va diferenciando de los otros y reflexiona sobre sí mismo y sus acciones. Integra las demandas sociales, valores y patrones de conducta, en base a lo que él mismo se considera y lo que desea llegar a ser. Al mismo tiempo construye su imagen considerando sus logros. Esa imagen y el valor que se da el niño es su autoestima (Veliz y Maureira, 2005). Al estar el niño mucho tiempo expuesto a la televisión lo priva de desarrollar muchas competencias que le ayudaran a formar su autoconcepto y autoestima, ya que no se le estimulará para adquirirlas.

\section{Consecuencias de la exposición a la televisión}

De acuerdo a lo expuesto anteriormente se evidencia que según las características de su edad los niños son una población significativamente vulnerable frente los efectos de la televisión; afectando las diferentes áreas de su desarrollo.

Los efectos de la televisión son múltiples, considerando que según White (1998), el ser humano es integral en su totalidad, existe una relación significativa en entre cada área de su desarrollo, lo que evidencia que los efectos de la televisión tiene una expresión mucho más amplia; sin embargo, por fines de investigación se ha restringido a los siguientes:

\section{Consecuencias psicológicas}

Al revisar algunos efectos psicológicos de la televisión
Torres y García (2009), hacen referencia a la publicación de la Asociación Española de Pediatría (AEP) que anunciaban que por "cada hora de consumo de televisión en niños entre 1 y 3 años incrementa un $10 \%$ las probabilidades de que presenten trastornos de atención a la edad de 7 años”. (p. 105).

De esa forma el funcionamiento de sus funciones cognitivas también se ven alteradas. El rendimiento académico de aquellos niños que ven más de 10 ó 15 horas de televisión al día disminuye significativamente, a diferencia de aquellos niños que pasan menos tiempo expuestos a la televisión (Rodríguez, 2005). A esto Clausell (2005), agrega que hay un declive de la capacidad de atención, concentración; coincidiendo al afirmar que la exposición a la televisión afecta el rendimiento académico.

Clausell (2005), continúa diciendo que al estar frente a la televisión los niños estimulan la expresión de reacciones violentas, eliminando aquellos que no le produce ninguna sensación placentera, ya que tienen la posibilidad de cambiar de canal las veces que sea necesario, ofuscando de esa forma el desarrollo de su inteligencia y voluntad. Al mismo tiempo por la rapidez en la que son presentadas las imágenes limita el tiempo de reflexión acerca de lo que se ve a diferencia de leer un libro, por lo que los niños evidenciarán falta de iniciativa, creatividad y reflexión al actuar.

Adicionalmente Ramírez (2007), también afirma que la televisión tiene una fuerte influencia en las conductas violentas:

A menudo nos vemos fuertemente influidos por las acciones de quienes nos rodean, la familia, la escuela, el ambiente de trabajo, los medios de comunicación, etc.; especialmente los niños aprenden a comportarse mediante el refuerzo directo y la observación de la conducta ajena. Estas diversas fuentes o componentes sociales servirán de modelos para sentimientos, pensamientos y acciones. Por tanto, la exposición al comportamiento ajeno en nuestro caso a la violencia divulgada en medios de comunicación puede desencadenar reacciones similares en quienes la observan, favoreciendo su adquisición y subsiguiente repetición, mediante el aumento de sentimientos hostiles y pensamientos agresivos (p. 443).

A parte de ello Veliz (2005), refiere que "la televisión trabaja el tema del género, lo transforma, lo da a conocer, lo manipula, lo diferencia, pero de una forma sutil y muchas veces inofensiva, como en el caso de los dibujos animados" (p.). Lo que significa que aquello que observan los niños en la televisión tiene influencia en su identidad de género, la que puede ser positiva o negativa. Asimismo Veliz (2005), continúa diciendo que "la televisión ayuda a que los niños adquieran determinadas creencias, valores y costumbres” (p. 46), intervinien- 
do mediante la presentación de conductas que pueden imitarse, proporcionando imágenes que provocan determinadas acciones y finalmente "es el medio por el que, a muy temprana edad, los sujetos se familiarizan con los valores de la sociedad del ocio y consumo" (p. 46). Siendo no precisamente valores edificantes para su desarrollo personal.

Por lo mencionado anteriormente, no es poco relevante la supervisión de los programas televisivos a los que están expuestos los niños en cada hogar.

\section{Investigaciones sobre los efectos de la televisión}

Al revisar las investigaciones sobre los efectos de la televisión se encontró a Sevillano y Perlado (2005), quienes realizaron una investigación de tipo descriptiva donde aplicaron como instrumento un cuestionario hecho por los mismos investigadores, a una muestra de 432 niños, con edades de 6, 7 y 8 años; de los centros educativos de Zaragoza (España) que cursaban el $1^{\circ}$, $2^{\circ}$ y $3^{\circ}$ de educación primaria. El objetivo fue describir las preferencias de los niños con edades comprendidas entre los 6 y los 8 años hacia los programas televisivos infantiles. Obteniendo como resultado que los niños prefieren programas infantiles caracterizados por tener más acción y violencia, más espontaneidad, manifestada en muchas ocasiones en actitudes inadecuadas de los personajes. El 22,9\% prefiere esos programas porque son "divertidos" y el 22,9\% porque les "causa risa”. El 81,5\% de los niños desearían parecerse a los personajes de sus programas favoritos.

En este mismo año Barbancho et al (2005), realizaron un estudio de diseño no experimental y de tipo correlacional sobre los hábitos televisivos en una muestra escolar de 10-14 años de Plasencia. Mediante una encuesta a los padres conocieron las preferencias de los productos alimenticios. Asimismo, se les realizó un examen antropométrico y medición capilar de colesterolemia, glucemia y tensión arterial. Los resultados evidenciaron que las niñas ven la TV y picotean golosinas. Asimismo, las niñas con sobrepeso ven más tiempo la TV.

Ramírez (2007), hace una revisión teórica a investigaciones previas de diseño experimental y no experimental y de tipo correlacional, con el objetivo de encontrar coherencia entre todas ellas y así relacionar el uso de la televisión y violencia en los niños. Concluyendo que la excesiva difusión de la violencia en los medios de comunicación durante la infancia pueda acarrear efectos a largo plazo, influyendo sobre el nivel de criminalidad en la vida adulta y en la violencia social, incluso puede explicar importantes diferencias sociales.
Adicionalmente el CONCORTV (Consejo Nacional de Radio y Televisión) (2010), realizó una encuesta dirigida a adolescentes, con la intención de jerarquizar el uso de los medios de comunicación. Sus resultaron concerniente a la muestra fueron que el $98.5 \%$ hace uso de la televisión y la radio en un 91.5\%, ubicándoles como los medios con mayor presencia y difusión. Le siguen el teléfono celular (77.8\%) y el DVD (77.4\%).

Fernández, Revilla y Domínguez (2011), en una investigación de diseño experimental y tipo descriptiva estudiaron ocho grupos focales a quienes se les expuso fragmentos de programas con violencia real o ficticia. $\mathrm{Su}$ objetivo era reconstruir la noción de identificación a partir de lo que ven las personas. Los resultados mostraron que la identificación está conectada a la posibilidad de experimentar la misma emoción e impacto de los personajes, según la similitud o preferencia de los espectadores.

Así también Quiroz (2011), hizo una investigación de diseño no experimental y tipo descriptiva con jóvenes adolescentes de las zonas rurales del Perú; con el objetivo de evaluar los efectos de la televisión en el medio rural de Perú, obteniendo que ésta tiene para los adolescentes y sus padres un signo positivo porque favorece la desterritorialización visual disminuyendo la relación natural entre cultura y territorio geográfico. En las zonas rurales los padres y los jóvenes valoran a la televisión porque les ofrece más que la propia escuela. Sin embrago, existe cierta vulnerabilidad puesto que no distinguen entre los medios tradicionales y nuevos.

\section{CONCLUSIONES}

De acuerdo a la revisión teórica presentada en este artículo sobre los efectos de la televisión en los niños se concluye que:

La excesiva e indiscriminada exposición a los programas televisivos pueden perjudicar significativamente las funciones cognitivas de atención, concentración y memoria de los niños, afectando directamente su rendimiento académico.

Asimismo su capacidad de reflexión se ve alterada siendo mucho más propenso a reaccionar en forma violenta.

Parte de la moral y la adquisición de valores se ve influenciada por la frecuente exposición a la televisión, siendo el ocio y el consumo los más propagados; aunque no precisamente una influencia positiva.

Finalmente, la televisión participa en la formación de la identidad de género de los niños, siendo que éste difunde de una manera distorsionada la percepción que ellos adopten sobre su identidad tendrá sesgos negativos. 


\section{REFERENCIAS BIBLIOGRÁFICAS}

1. Barbancho, F., Prieto, J., Tirado, F., Hernández, L., Santos, J. \& Moreno, A. (2005). Efectos de la televisión sobre la alimentación, la obesidad y colesterolemia en niñas escolares. Cultura de los cuidados, España. 18 (2), p.1. Recuperado de: http:// www.scirus.com/srsapp/search?q=efectos + de + la + television \&t=all\&drill=yes\&sort $=0 \& \mathrm{p}=0$.

2. Centro Regional de Innovación y Formación ACASIA (2008). Recuperado de: crif.acacias.educa.madrid.org/.

3. Clausell, A. (2005). Los efectos de la televisión en la infancia y en el rendimiento escolar. La familia. Pautas educativas y de interacción. II. Asociación de madres y padres el armelar, p. 1-11. Recuperado de: http://www.ampaelarmelar.org/Charlas2005/ MATERIAL_TV_para_padres.pdf.

4. CONCORTV (Ed.) (2010). Encuesta sobre las actitudes, hábitos, evaluación y opinión hacia la radio y televisión en el Perú. Recuperado de: www. concortv.gob.pe.

5. Diccionario etimológico de Chile. Recuperado de: http://etimologias.dechile.net/?television.

6. Fernández, F. (1994). Clase social, exposición a la televisión y percepción de la violencia en la televisión. España: Estudios sociales.

7. Fernández, C., Revilla J. \& Domínguez R. (2011). Identificación y especularidad en los espectadores de violencia en televisión. Comunicación y sociedad Revista de la Facultad de Comunicación. 1 (24), p.7-32. Recuperado de: http://dialnet.unirioja.es/servlet/articulo?codigo $=3674840$.

8. Martínez, J. (2007). Televisión y violencia. Revista Latinoamericana de Psicología. 2(39), p. 327-349. Recuperado de: http://eprints.ucm.es/8416/1/311_ JMR_Televisio\%CC\%81n_y_violencia.pdf

9. Perlado, L. (2003). El mensaje televisivo infantil. Análisis, percepción y efectos en los niños de 6 a 8 años en Zaragoza. (Tesis inédita de doctorado). Universidad Nacional de Educación a Distancia, Madrid, España.

10. Piaget, J. (1972). Estudios de psicología genética. Buenos Aires: Emecé.

11. Quiroz, M. (2011). La televisión: vista, oída y leída por adolescentes peruanos. Revista Científica de Educación y Comunicación, 36 (18). Recuperado de: http://dialnet.unirioja.es/servlet/busquedad oc?t=La+televisi $\%$ C3 $\%$ B3n $\% 3 \mathrm{~A}+$ vista $\% 2 \mathrm{C}+\mathrm{o} \%$ $\mathrm{C} 3 \% \mathrm{ADda}+\mathrm{y}+\mathrm{le} \% \mathrm{C} 3 \% \mathrm{ADda}+\& \mathrm{db}=1 \& \mathrm{td}=$ todo.

12. Ramírez, J. (2007). Televisión y violencia. Revista Latinoamericana de Psicología, 2 (39), 327-349. Recuperado de: http://dialnet.unirioja.es/servlet/ articulo? codigo $=2539744$.

13. Rodríguez, A. (2005). Los efectos de la televisión en niños y adolescentes. Revista Científica de Educación y Comunicación, 25 (1). Recuperado de: http:// dialnet.unirioja.es/servlet/articulo?codigo $=2925013$.

14. Rodriguez, P. \& Ruiz A. (2005) La televisión: ¿caja tonta o caja mágica?, Revista Científica de Educación y Comunicación , 25(1). Recuperado de: http://redalyc.uaemex.mx/redalyc/src/inicio/ IndArtRev.jsp?iCveNumRev=10486\&iCveEntRe $\mathrm{v}=805$ \&institucion.

15. Sevillano M. \& Perlado L. (2005). Los programas televisivos infantiles preferidos por los niños de 6 a 8 años. Revista Científica Iberoamericana De Comunicación y Educación, 25(2), 1-9. Recuperado de: http://dialnet.unirioja.es/servlet/ articulo?codigo $=2778877$.

16. Tallaferro, A. (2001). Curso básico psicoanálisis. España: Paidós.

17. Torres, M. y García, R. (2009). El vínculo infancia televisión en la sociedad actual. Análisis de la programación televisiva infantil española, 27 (2), p. 103-122. Recuperado de: http://dialnet.unirioja. es/servlet/articulo? codigo $=3232165$.

18. Veliz, C. \& Maureira, A.(2005). La televisión como agencia de socialización: impacto de su rol socializador en el comportamiento de niños y niñas durante la jornada escolar. (Tesis inédita de licenciatura).Universidad de Chile, Santiago de Chile, Chile.

19. Vilain, R. (2001). Universidad de Concepción Chile, recuperado de: http://www.udec.cl/ivalfaro/ apsique/desa/nitv/html.

20. Vilches, L. (1999). Los efectos del bien y el mal. España: Ediciones Paidós.

21. White, E., (1998). Hijas de Dios. Buenos Aires: Casa Editora Sudamericana 